\title{
THE IMPACT OF SOCIAL NETWORKS ON THE SOCIAL HEALTH OF ADOLESCENTS AND YOUNG ADULTS IN ARDABIL
}

\author{
Vahid Abolhasanzadeh \\ Yazd University, Iran \\ vabolhasanzade@gmail.com \\ Javad Maddahi \\ Yazd University, Iran \\ gmaddahi@yahoo.com \\ Hamid Mohammadi \\ Yazd University, Iran \\ Hamidsafar17180@gmail.com
}

\begin{abstract}
The objective of this study is to identify the effects of virtual social networks on the social health of young people. And the question, "Do virtual social networks effect the social health of young people", is addressed. The main hypothesis of this study is: "There is a relationship between the rate of using virtual social networks and the social health of youth." The theoretical framework of this study is based on the theories of Keyes, Giddens, and Larson regarding social health, and communication skills theories of Schneider, Berkman, Bartle, Giddens, and the network view and social model of Wellman regarding virtual social networks. In this study, which is a field study, 800 young people from Ardabil in 2014-2015 were selected, using the cluster sampling method. Data was gathered using the Keyes social health questionnaire and a questionnaire regarding virtual social networks. The obtained social health of young people followed an approximate normal distribution. There is a statistically significant relation between relating with friends, internet advertisements, social involvement, negative behavioral effects, invading individual privacy, income, and education with young people's social health. In regression analysis, the variables that form the model, determined about $19 \%$ of the changes in the variance of social health. The strongest predicting variables were: relating with friends, and internet advertisements. We can conclude that the social health of young people, as a social construct, is effected positively and negatively by virtual social networks.
\end{abstract}

Keywords: Social health, social networks, effects, adolescents, Ardabil

\section{INTRODUCTION AND PROBLEM STATEMENT}

The center of sustainable development is a healthy person. Modern societies wish to create a favorable environment for production and the necessary acceleration to achieve comprehensive development. "Health is where all human efforts takes place in it and if there is an acceptable level of health, people will be able to benefit from other sources of life" (Babai, 2003). The most widely accepted definition of health is the one by World Health Organization: "Health is a welfare state of complete physical, mental and social and not merely the absence of disease or disability" (Habrsak, 2013).

Today, social health as one of the aspects of health, along with physical, mental, and spiritual health has received great importance, so that health is no more just lacking physical and mental problems health is not just freedom from disease, but also how human acts in social relations and his thought about the community are known health assessment criteria at large scale of community (Samaram, 2009).

In general, the social dimension of health includes levels of social skills and performance and the ability to recognize oneself as a member of the larger community. In this regard, any person is a 
member of the family and the member of a larger community. Given that social health emerges in the context of society and the relations between persons in social networks, then we can say that social relationships and virtual social networks can also be one of the factors affecting people's social health. With the vast expansion of social networks, in the present age, especially among young people, along with increasing social problems that arise from this technology and the virtual world to control and deal with it, interaction, and how to use it must be studied and taught the people especially the younger generation (Gholizadeh, 2015: 6).

Presence in cyberspace and the use of the Internet use, especially in the Third World cities, whether with professional motivation, with entertainment motivation, whether continuous or temporary, according to the features, characteristics and facilities unique to this space profound effects are made on different aspects of identity and consequently, the lifestyle of Iranians, especially young. In fact, Iranian users, according to objective and subjective structures in the real world and according to the type and extent of their use of the Internet receive a wide range of influences and changes gradually (Khatibi, 2005: 10).

In addition, social networks can play an important role in meeting the physical, psychological, social, and economic needs. Network members can directly help a person and assist him in spreading his calls and somewhat overcome his personal deficiencies in her family background (Power, 1988). In contrast, the rapid and comprehensive development of social networking among young people has raised questions about its possible implications for users and society. These technologies have changed lifestyles of young people more than the other traditional life styles. Thus, an interesting question is how young people build their identity in a technological world, which ultimately affects the health of their community (Amirpour, 2013).

Social health importance is so much that young people enjoying the social health can cope with problems caused by the main social role more successfully. They live in families that have more stability and possibly can participate in more activities that are social and their compliance with social norms expects to be more. This can play an important role in preventing diversions that extends beyond the realm of individual behavior (Abdullah Zadeh, 2008).

\section{THEORETICAL BASICS}

In this study, five-part Keynesian theory is used as a model for defining and providing indicators of social health concept. Then, using the ideas of Halbwachs, Berkman, Giddens, Larson, Wellman, Bartley, ecology perspective and the perspective of the network, its relationship with economic status, education, gender, and particularly social network effects have been dealt with. Keynesian measure of social health at the individual level is five including 1) Social prosperity: social prosperity is assessing the potential of social evolution and the belief that society is in a gradual evolution and has the potential for positive changes that can be identified through social institutions and citizens. Healthy people are hopeful about the future of society and able to identify collective forces and believe that other people of the community will benefit from these forces and development (Tabardarzy et al., 2007). 2. Social Compliance: understand the quality, organization, and functioning of the social world are concerned in this aspect. Socially, healthy citizen tries to have more information about the world around them, to link them to others in the same community (Keynesian, 2004). In this aspect of public health, the perspective of ecology that emphasizes the individual's connection with the environment is used. In human ecology, environmental and human interdependence and mutual interaction are studied. 3. Social acceptance: this aspect of public health points out that the social version of selfacceptance is acceptance of others. In fact, people who have a positive attitude to their character and accept both good and bad aspects of life are people with mental and social health (Hezarjaribi, et al., 2012). Virtual reality and functions of this way can act in making abnormal assumptions about identity. People in virtual chat rooms could change to ones as exactly they want or exactly how they want other people to see them. 4. Social participation: in social participation, people feel that they have something valuable to offer to the community, citizens think that in their daily activities, the community values them. In the definition social participation, Halbwachs states that it is the values of community where the person is a member. If the people live within their values and norms, in fact, 
they have participated in social life (Tavassoly, 2003). Accordingly, community participation is the belief through which the person knows himself as a vital member of the community and these people are trying to feel loved and to be involved in a world solely for their human values (Samaram, 2009). Berkman said that by joining social networking opportunities will be provided to individuals, to participate in community events, significant social roles, social roles such as work, family and parenthood is defined this way individual social health are improved (Kheirollah Poor, 2006: 43). 5. Social cohesion: evaluation of a person is with regard to quality of his accompanying with the surrounding community. Social cohesion is individual assessment of the quality of social relations and social groups. Healthy person feels that he is a part of community and knows himself as common to others who make up the social reality.

The main block of the network is connection and network perspective studies social relationships between groups of individuals to analyze the social structure. This view believes that social processes of personal consequences, in spite of constant personal characteristics such as gender, essentially are defined through the patterns of relations between actors in social networks (Salehi, 2005).

Wellman believes that, at present, there is a kind of anxiety and concern for the community and people in the modern world have always feared, lest their society excludes them and encounter loneliness and alienation. Wellman, in the social abandoned model, believes that relations in the modern world cities are neither entirely gone nor predominantly have rural and neighbor use, but have dispersed state and less neighborhood can be seen. In the abandoned community, people are members in multiple groups based on their interest. Network analysis view deals with community with this approach and believes that the community is not gone but has changed from neighborhood and neighbor state to scattered, dense and less bounded deformed and drastic social changes have failed to changes in the pattern and structure their relationships rather than destroy it completely (Gholizdeh, 2015). In Bartel's idea, the secret to the success and attract users to major websites is that the users see himself in the virtual world mirror. Thus, on identity in the virtual world, the question is to what extent the user likes the reflection of his image in the mirror. Giddens believes that virtual social networks by offering an empty container for the audience provide the opportunity for the user to fill the content and message as they wish to produce. Alternatively, by changes in the motif of the content and information going around in the world of the person, the form and type of communication change. In these circumstances, one can not expect that people's connection components together or separated by distance of time and place as considered by Giddens, the same type of communication and communication networks to bring that, in the traditional world view (Hosseinpur , 2010).

Rose and $\mathrm{Wu}$ suggest that people with higher education compared to those with low literacy in terms of psychological and social health are in a better position. In other words, a person's position in the social hierarchy provides conditions and characteristics that can overshadow his health. Schneider and colleagues define communication skills as the relationship between the individual and the environment and as a means to launch and sustain a constructive relationship, and as an important part of public health. This has been used to explain the relationship between social networks with social adaptation (Hatami, 2010: 11).

\section{RESEARCH BACKGROUND}

Social health is a concept that beside the physical and mental health studies social aspects by focusing on individual health. The findings of Taylor (2012) show that social networks, combined with the influence of Western powers, have begun to move to the homogenization of the world. This move would create conflict in the world and move of some nations to defeat and the weakening of their national identity and traditions that may endanger their social health. In addition, he believes that, through these social networks, significant people around the world interact with each other, faced with an alien culture and beliefs, and are alarmed about the loss of their religious and national identities.

Garrido and Azpiazou results show that the general health status of women is lower than men in terms of socio-economic status and educational level (Garrido and Azpiazou, 2002). Income, occupation, education, and age are associated with public health. 
According to Adler et al. (1994) and Anderson and Starr (1996), the underclass have lower public health and the health of mineworkers is never as much as doctor and university professor (Karayeb, 2004). Fixed employment plays a major role in social skills, experience, and social networks, and as a result, social health of individuals. Employment in top positions and as a result, more money also plays a role in the formation of healthy identity and self-esteem.

Hellman (1994) argues that low level of education is associated with poor social health, poverty, poor distribution of income, high levels of unemployment, lack of social security and low levels of literacy are among the factors affecting public health (Wilkinson, 1996).

Jomehnia (2008) studied the relationship between social health and identification styles of high school students of Gonbad. The results showed that between girls and boys, in terms of public health in participation and social cohesion, there is a significant difference, while there was no significant difference between girls and boys in social reception and prosperity and social compliance of other aspects of social health.

Moreover, there is a significant relationship between social health and identification style. According to research by Azhir, male and female students in Sanandaj have no significant difference in terms of public health (Azhir, 2006).

\section{RESEARCH METHODOLOGY}

In this study, Considering that the our goal is to assess the relationship between impact of social networks on social health youth, is used Traversal method. In order to collect data are used the questionnaire and gather information related to theoretical discussions used the Internet search and the library. In this study to measure social health variables is used Keyes (1998) Standard questionnaire. Item reliability of the questionnaire was estimated through The content validity method Of formal. The number of our sample selected 800 adolescents and young adults in Ardabil by cluster sampling and were measured.

In the present study, Cronbach's alpha was calculated, using data from preliminary tests with the help of computers and software spss. To chart a path analysis is used Amos software.

\section{RESULTS AND FINDINGS}

Sex: There is a difference between sex and social health of young people. In order to compare the average social health of man and woman, was used t-test 2 . The results of these tests are shown in Table 3.

Table 3. Output $t$ test to compare the social health of young people by gender

\begin{tabular}{c|c|c|c|c|c|c|c}
\multirow{2}{*}{ Dimension } & $\begin{array}{c}\text { Categorie } \\
\text { s }\end{array}$ & Number & Average & $\begin{array}{c}\text { Standard } \\
\text { deviation }\end{array}$ & $\mathrm{t}$ & $\begin{array}{c}\text { Degrees of } \\
\text { freedom }\end{array}$ & $\begin{array}{c}\text { significanc } \\
\text { e level }\end{array}$ \\
\hline Social Health & Man & 551 & $77 / 78$ & $6 / 726$ & $12 / 168$ & 798 & $0 / 000$ \\
\cline { 2 - 5 } & Female & 249 & $70 / 78$ & $9 / 065$ & & & \\
& & & & & & &
\end{tabular}

As the above table, it is clear from the findings of independent t-test results, that the social health mean women and men are different and the social health men is more than women.

\section{Family income and social health}

There is a relationship between education and social health of young people. The variable income is expected to have a significant role on the social health respondents. So to evaluate the correlation between income and social health of the respondents have used Pearson correlation test results that are shown in Table 4.

Table 4. Correlation matrix between the income and social health 


\begin{tabular}{c|c|c|c|c|c|c} 
Dimensions & Flourishing & acceptance & participation & acceptance & cohesion & social health \\
\hline income & $0 / 011$ & $0 / 113^{* *}$ & $0 / 102^{* *}$ & $0 / 117^{* *}$ & $0 / 097^{* *}$ & $0 / 081^{*}$
\end{tabular}

According to the table above, between the family income and social health was obtained the significant and positive correlation. In other words, High income, promote social health of humans.

\section{Education and social health}

There is a relationship between Education and social health of young people. In order to determine the relationship between the use of social networks and social health was used the Pearson correlation coefficient. The results of these tests are shown in Table 4.

Table 4. Matrix correlation between education level and social health

\begin{tabular}{c|c|c|c|c|c|c} 
Dimensions & Flourishing & acceptance & participation & acceptance & cohesion & social health \\
\hline education & $0 / 027$ & $0 / 160^{* *}$ & $0 / 137^{* *}$ & $0 / 133^{* *}$ & $0 / 086^{*}$ & $0 / 188^{* *}$
\end{tabular}

A significant inverse correlation is a result between education level of respondents and the social health that is evidenced by the table above. In other words, the social health of individuals is reduced If the respondents higher education.

\section{Social Networking and Social Health}

There is a relationship between the use of virtual social networks and social health of young people. In order to determine the relationship between the use of social networks and social health was used of the Pearson correlation coefficient. The results of these tests are shown in Table 5.

Table 5. The correlation matrix between the use of social networking and social health

\begin{tabular}{c|c|c|c|c|c|c} 
Dimensions & Flourishing & acceptance & participation & acceptance & cohesion & social health \\
\hline $\begin{array}{c}\text { Relationships with } \\
\text { friends }\end{array}$ & $0 / 233^{* *}$ & $0 / 132^{* *}$ & $0 / 064$ & $0 / 207^{* *}$ & $0 / 107^{* *}$ & $0 / 258^{* *}$ \\
\hline $\begin{array}{c}\text { Development of } \\
\text { partnerships }\end{array}$ & $0 / 057$ & $0 / 130^{* *}$ & $0 / 377^{* *}$ & $0 / 236^{* *}$ & $0 / 069^{*}$ & $0 / 249^{* *}$ \\
\hline Internet advertisement & $0 / 083^{*}$ & $0 / 447^{* *}$ & $0 / 257^{* *}$ & $0 / 070^{*}$ & $0 / 001$ & $0 / 247^{* *}$ \\
\hline Education & $0 / 048^{*}$ & $0 / 126^{*}$ & $0 / 019$ & $0 / 191^{* *}$ & $0 / 108^{*}$ & $0 / 140^{* *}$ \\
\hline Promote rumors & $0 / 003$ & $0 / 091$ & $0 / 081$ & $0 / 125^{*}$ & $0 / 049$ & $0 / 090$ \\
\hline $\begin{array}{c}\text { Anti-religious } \\
\text { propaganda }\end{array}$ & $0 / 003$ & $0 / 091$ & $0 / 081$ & $0 / 125^{*}$ & $0 / 049$ & $0 / 090$ \\
\hline $\begin{array}{c}\text { Privacy Violation } \\
\begin{array}{c}\text { The negative impact } \\
\text { behavior }\end{array}\end{array}$ & $0 / 009$ & $0 / 326^{* *}$ & $0 / 228^{* *}$ & $0 / 253^{* *}$ & $0 / 016$ & $0 / 289^{* *}$ \\
\hline Positive impact network & $0 / 024$ & $0 / 271^{* *}$ & $0 / 209^{* *}$ & $0 / 350^{* *}$ & $0 / 112^{*}$ & $0 / 319^{* *}$ \\
\hline negative impact network & $0 / 040$ & $0 / 239^{* *}$ & $0 / 194^{* *}$ & $0 / 187^{* *}$ & $0 / 041$ & $0 / 195^{* *}$
\end{tabular}

The significant positive correlation between the use of virtual social networks and social health, a result that is evidenced by the table above. In other words, the use of social networks have a positive and negative impact on social health. This result confirms the hypothesis. Other columns above table shows the correlation of social networking Dimensions and social health.

\section{Regression}


In this section, the multivariate regression was used to explain the factors set. Multivariate regression is a statistical method that considers how independent variable Explained dependent variable changes as well as how much is the effect of each of them. To achieve this goal were used the stepwise regression methods. The impact of social networking on social health of The regression results with stepwise is shown in the table below.

Table 8. Results of multivariate regression analysis to assess the effect of independent variables

\begin{tabular}{|c|c|c|c|c|c|}
\hline \multirow{3}{*}{ Dimensions } & \multirow{3}{*}{$\mathrm{B}$} & \multicolumn{2}{|c|}{ on social health } & \multirow{3}{*}{$\mathrm{T}$} & \multirow{3}{*}{ Sig } \\
\hline & & \multirow{2}{*}{$\begin{array}{l}\text { Std. } \\
\text { error }\end{array}$} & Standardized coefficients & & \\
\hline & & & Beta & & \\
\hline $\begin{array}{l}\text { Relationships with } \\
\text { friends }\end{array}$ & $0 / 627$ & $0 / 096$ & $0 / 211$ & $6 / 525$ & $0 / 000$ \\
\hline Internet advertisement & $0 / 564$ & $0 / 087$ & $0 / 211$ & $6 / 520$ & $0 / 000$ \\
\hline $\begin{array}{c}\text { Development of } \\
\text { partnerships }\end{array}$ & $0 / 568$ & $0 / 094$ & $0 / 196$ & $6 / 035$ & $0 / 000$ \\
\hline education & $1 / 467$ & $0 / 350$ & $0 / 135$ & $4 / 185$ & $0 / 000$ \\
\hline $\begin{array}{c}\text { The negative impact } \\
\text { behavior }\end{array}$ & $0 / 227$ & $0 / 088$ & $0 / 085$ & $2 / 567$ & $0 / 010$ \\
\hline Privacy Violation & $0 / 221$ & $0 / 097$ & $0 / 075$ & $2 / 272$ & $0 / 023$ \\
\hline
\end{tabular}

\begin{tabular}{c|c|c} 
coefficient & R Square & Adjusted R Square \\
\hline $0 / 439$ & $0 / 192$ & $0 / 186$
\end{tabular}

Based on the above table, the coefficient of correlation between independent variables and social health variable equal to $\mathrm{R}=0 / 439$ and Adjusted $\mathrm{R}$ Square equal to $\mathrm{R}=0 / 186$ is obtained. And indicates that $19 \%$ of the variance of social health variable determined by the independent variables. The regression model explained by ANOVA, linear and significant. Because the F-test for independent variables explain a significant effect on social health is equal to $31 / 488$ with significance level $\mathrm{P}$ $=0 / 000$. Finally, with respect to Beta values of the independent variables in the table above; Relationships with friends Beta $=0 / 211$, Internet advertisement Beta $=0 / 211$, Development of partnerships Beta $=0 / 196$, education Beta $=-0 / 135$, The negative impact behavior Beta $=-0 / 085$, Privacy Violation Beta $=0 / 075$, Have the greatest impact on social health.

The findings related to structural equation modeling assumptions: In this section, findings related to the main hypothesis and sub-hypotheses of hypothetical model presented.

\begin{tabular}{l|r|r|r|r|r|r|r|r|r}
\multicolumn{1}{c}{ Table 9. Goodness of Fit Index for supposed model } \\
RMR & RMSEA & NFI & CFI & AGFI & GFI & X $/$ df & $X^{2}$ & Index \\
\hline $0 / 449$ & $0 / 054$ & $0 / 86$ & $0 / 90$ & $0 / 96$ & $0 / 98$ & $3 / 33$ & $63 / 42$ &
\end{tabular}

The Result of main hypothesis study: The aim of this research was to develop a clear understanding of how is The Effect of Social Network on social health. Path analysis will show whether the main hypothesis of this study - model fit with data obtained from the sample of study- will be confirmed? Although simple relationships between variables revealed to us some hints, but manifold and complex relationships between variables revealed through the Path analysis. The results of Path analysis based on correlation matrix between the variables showed that The model have a Good fitness with the data. 


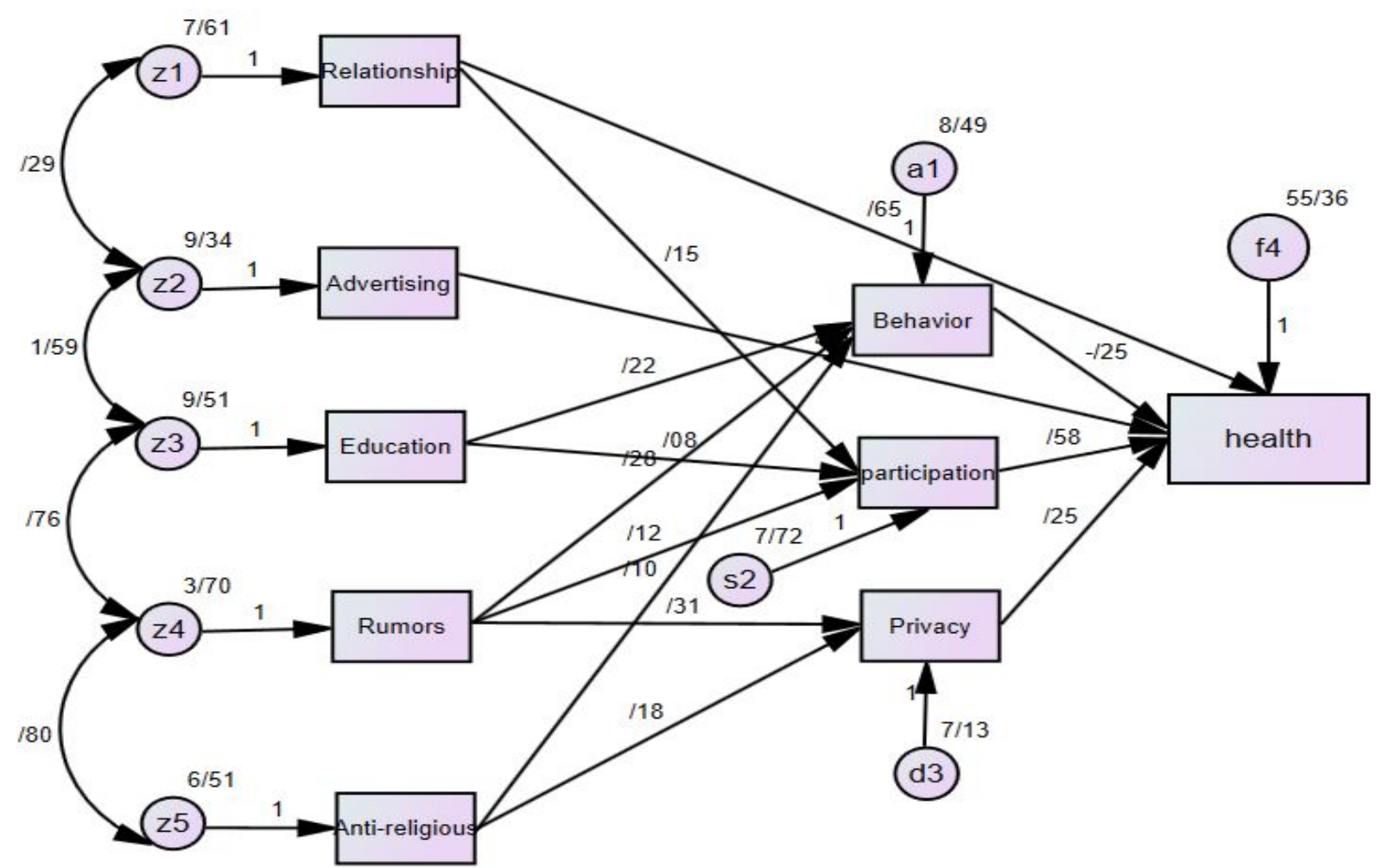

Figure 1. Path graphs of the relationship between the social network and social health

The Result of the secondary hypothesis study: In the table below, the direct and indirect effects of the aspects of social networking on social health has been shown. The numbers in parentheses indicate the $t$ test. As can be seen, variables of the relationship with friends, Development of partnerships, Internet advertisement, Privacy Violation and The negative impact behavior, have direct and significant impact and variables of education, promote rumors, anti-religious propaganda, have indirect impact on the dependent variable. Variables of the relationship with friends, promote rumors and education have a direct impact on the development of social partnership. Also, variables of the anti-religious propaganda and promote rumors have significant direct impact on the variable privacy violations. Finally, the variable anti-religious propaganda, promote rumors and educations, have a direct impact on the negative impact behavior.

Table 10. direct impact, indirect impact and the total impact of predictor variables

\begin{tabular}{lccc}
\hline variables & direct impact & indirect impact & total impact \\
\hline On social health & & & \\
\hline Relationships with friends & $(6 / 71) 0 / 219$ & $0 / 028$ & $0 / 247$ \\
$\begin{array}{l}\text { Development of partnerships } \\
\text { Internet advertisement }\end{array}$ & $(6 / 16) 0 / 201$ & & $0 / 201$ \\
$\begin{array}{l}\text { education } \\
\text { promote rumors }\end{array}$ & $(6 / 99) 0 / 226$ & $0 / 003$ & $0 / 226$ \\
$\begin{array}{l}\text { anti-religious propaganda } \\
\text { Privacy Violation }\end{array}$ & $0 / 018$ & $0 / 003$ \\
$\begin{array}{l}\text { negative impact behavior } \\
\text { development of social partnership }\end{array}$ & $(2 / 62) 0 / 085$ & $0 / 006$ & $0 / 018$ \\
\hline $\begin{array}{l}\text { Relationships with friends } \\
\text { promote rumors }\end{array}$ & $(2 / 90) 0 / 094$ & & $0 / 006$ \\
$\begin{array}{l}\text { education } \\
\text { On Privacy Violation }\end{array}$ & $(4 / 07) 0 / 142$ & $0 / 095$ \\
\hline anti-religious propaganda & $(2 / 44) 0 / 081$ & & $0 / 142$ \\
promote rumors & & & $0 / 081$ \\
On negative impact behavior & $(4 / 69) 0 / 161$ & $0 / 086$ \\
& $(6 / 28) 0 / 216$ & & $0 / 161$ \\
\cline { 2 - 3 } & & & $0 / 216$
\end{tabular}




\begin{tabular}{|c|c|c|}
\hline anti-religious propaganda & $(2 / 49) 0 / 085$ & $0 / 085$ \\
\hline promote rumors & $(5 / 12) 0 / 176$ & $0 / 176$ \\
\hline education & $(6 / 43) 0 / 218$ & $0 / 218$ \\
\hline
\end{tabular}

\section{CONCLUSION}

In this study, 800 adolescents and young adults in Ardabil were studied. $68.9 \%$ were male and $31.1 \%$ were female, in terms of family income, 50 percent of respondents reported family income over three million tomans showing that the majority of respondents have high income. In terms of education, $69 \%$ of respondents have reported high school and diploma. Most respondents in terms of public health are at average to above reflecting that the positive effects of social networks were more than the negative effects.

First hypothesis based on a significant difference between genders in terms of public health was confirmed. Therefore, according to the findings of this study, social health scores between men and women are different. This is consistent with the findings of Garrido and Azpiazou, 2002, Jomenia, 2008).

The second hypothesis test result suggesting the relationship between education and social health was rejected. This result of the study is not consistent with the findings of Garrido and Azpiazou, 2002; Hellman, 1994; Adler et al., 1994; Anderson and Starr, 1996. So that by increasing education, social health is threatened, perhaps the main reason for this is that, after graduating people want social expectations and status and goals better than the others, and according to Merton as the tools of achieving these objectives is not possible, people are hurt as a result of which their social health is compromised. The third hypothesis is about the relationship between income and social health of people. The results of this study support the relationship between the two variables. These findings are consistent with results of Garrido and Azpiazou, 2002; Adler et al., 1994; Anderson and Starr, 1996. According to Adler and Anderson and Starr (1996), people of low class have less social health and the health of mine workers is never as much as doctor and university professor (Karayab, 2006). In the study, given that, most of the respondents had reported earnings above 3 million tomans, they will have higher social health and social health of the respondents in this study was reported to be moderate to high. That is as the average income of people increases, their social health increases as well.

Another result of the study is the relationship between the social network and social health, which is the fourth hypothesis. This variable is compose of virtual communication with friends and acquaintances, the development of social partnership, targeted online ads, education, rapid formation and distribution of rumors and false news, anti-religious propaganda and instill of doubts, violation of privacy and negative behavioral impact. The scale of the variable and its relation to social and health status are outlined. According to the findings of the research results, significant correlation was observed between the use of virtual networks and social health of individuals consistent with the findings of Taylor, 2012; McDonald et al., 1978. Larson defines social health as the quality of person's relationships with other people (relatives and community groups) that he is a part of them and believes that social health scale measures a part of person's health and includes inner responses of the person that indicate satisfaction or lack of satisfaction with life and the social environment (Larson, 1996). Based on the model of "abandoned community" by Wellman, in the abandoned community people are members in multiple groups based on their interested, followed by the view of network analysis believing that the community has never gone away, but have changed from local and neighborhood state to border, scattered, less dense and bounded form. Great social changes have both failed to make changes in the pattern and structure of their relationships and to destroy it. Therefore, we can say that lifestyle of the people has changed and social networks can have a positive and negative impact for individuals. In this paper, the positive effects of social networks such as continuous virtual connection with friends and acquaintances, web development, social participation, and online targeted advertisements are directly connected with public health and the dependent variable. This show the positive impact of virtual social networks on social health, which can be used as a modern tool to promote social well-being of individuals and society to be employed, so that healthy people feel that 
they are a part of society. Therefore, social health is an area where people feel they have something in common with others and belong to community and social groups (Keynesian, 1998). Of course, the negative impact of behavioral variables and violation of privacy indirectly affect social health, but their impact has been very weak. Social health of adolescents and young adults has almost been normal and obtained as moderate to high. A significant relationship is proved between communication with friends, online targeted advertising, development of social partnership, the negative behavior impact, violation of privacy with their social health. In the regression analysis, variables in the model have been able to explain about 19 percent of variance of social health, where the strongest predictors are communicating with friends and targeted advertising. Therefore, we can say that adolescents' health as a social construct is affected by the positive and negative effects of social networks.

\section{REFERENCES}

Amirpour, M., Maryam Gryvany, (1392), the impact of social networks on the lifestyle of young people, the Quarterly Disciplinary Knowledge North Khorasan, 23-39.

Tabardarzi, Hadi Abdullah, 1386, to investigate the relationship social health and socio-demographic variables of Welfare and Rehabilitation Sciences University, MA thesis, University of Social Welfare and Rehabilitation Sciences.

Ajir, L. (1385). Gender beliefs, self-expression and social health of students, Master's thesis, Tehran University Faculty of Education and psychology.

Babaei, n. (1382), the health needs of adolescents in the context of social changes, social welfare Quarterly, Volume 2 (7).

jomehnia, S. (1387) explores the relationship between social health with Styles identity of students in public high schools Gonbad, master's thesis, Faculty of Psychology and Educational Sciences, Shahid Beheshti University.

Sam aram, A. (1388), Journal of social discipline, year 1 (1).

Abdullah Zadeh, H. (1387), the concept of social health, /psychologyinfo.blogfa.com /post152asp. (April, 2010,20).

Craib, Ian. (1383), modern social theory from Parsons to Habermas, (Translation A. rapporteur), Tehran informed.

Salehi, M. (1384). Examine the relationship between social capital of the network and interpersonal trust and gender, MS Thesis Al-Zahra University.

Khatibi jafary, F (1384), "modern identity and cyberspace" investigate the relationship between the presence in cyberspace and modern identity formation among iranian young users, ms thesis, Allameh Tabatabaei University, Faculty of Social Sciences.

Kheirollah Pour, A. (1385). Study of the Social factors affecting mental health with an emphasis on social capital "A Case Study of Shahid Beheshti University students', master thesis, Faculty of Literature and Humanities.

Hatami, P. (1389). Look at the history of social networks, web magazine, No. 150, pp. 72-75.

Hezarjaribi, J. and Safari Shali, R. (1391). Study of Virtual Addiction among adolescents and young adults in Qom, Journal of Social Sciences of Allameh Tabatabai University, No. 57.

Habersack M, Luschin G. 2013. WHO-definition of health must be enforced by national law: a debate. BMC Med Ethics; 14:24-8.

Keyes , C . M \& Shapiro , A . ( 2004 ), ' Social Well- being in the U.S : A Descriptive Epidemology' . In orvill Brim , Carol D . Ryff \& Ronald C . Garrido, M. and Azpiazo. (2002), Using the SF-36 With Older Adults: Across- Sectional, Community- based Survey, Age \& Aging, British Geriatrics Society. Larson, J.S. (1996), The World Organization Definition Of Health: - Social Versus Spiritual Health, Social Indicator Research, 38.

Wilkinson, R.G. (1996), Unhealthy Societies: from Inequality to well-being Routledge, London. Pempek, T., \& et al. (2009), «College students' social networking experiences on .Facebook», Journal of Applied Developmental Psychology, $30: 227-238$.

Tyler, T. (2012). "Social networking and Globalization", Mediterranean Journal of Social Sciences, Vol. 4, No. 6, July 2013.

Holmes, David. (2005) "Comunication theory medya" Technolagy and society, P 46-47. 